\title{
Abdominal Circumference as a Screening Measure for Type 2 Diabetes
}

\section{Ghosh JR, ${ }^{1}$ Bandyopadhyay AR ${ }^{2}$}

${ }^{1}$ Department of Anthropology

Visva-Bharati University, Santiniketan

West Bengal, India

${ }^{2}$ University of Calcutta, Kolkata

West Bengal, India

\section{Corresponding Author}

Jyoti Ratan Ghosh

Department of Anthropology

Visva-Bharati University

Santiniketan-731235

Birbhum, West Bengal, India

Email: jrghosh@rediffmail.com

Citation

Ghosh JR, Bandyopadhyay AR. Abdominal Circumference as a Screening Measure for Type 2 Diabetes. Kathmandu Univ Med J 2012;10(4):12-15.

\begin{abstract}
Background

No comparative study has been conducted in India considering different anthropometrically derived adiposity measures to study the association with Type 2 Diabetes.
\end{abstract}

\section{Objective}

This study aims to examine the association of different adiposity measures and to find out the best adiposity measure in assessing Type 2 Diabetes.

\section{Method}

On 187 adult males aged 25-67 years, fasting and two hours postload glucose levels were assessed. Height, weight, hip circumference, and waist circumference at two anatomical sites, one at the level of the greatest anterior extension of the abdomen i.e. abdominal circumference and the other one at the narrowest part of the torso i.e. minimum waist circumference were measured. Waist hip ratio, body mass index, waist height ratio and conicity index were calculated subsequently.

\section{Results}

The prevalence of Type 2 Diabetes was $12.3 \%$. Abdominal circumference revealed the highest odds ratio (OR $2.75 ; 95 \% \mathrm{Cl} 1.45$ - 5.23) for Type 2 Diabetes, followed by waist height ratio (OR $1.86 ; 95 \% \mathrm{Cl} 1.05-3.32$ ) and minimum waist circumference (OR 1.83; $95 \% \mathrm{Cl} 1.03-3.26$ ). The area under the receiver operating characteristic curve of abdominal circumference was also larger $(68 \% ; 95 \% \mathrm{Cl}$ : $0.57-0.79)$ compared to other adiposity measures in assessing Type 2 Diabetes.

\section{Conclusion}

Waist circumference measured at the level of greatest anterior extension of the abdomen was the best central adiposity measurement in predicting and assessing Type 2 Diabetes.

\section{KEY WORDS}

Abdominal circumference, central adiposity, Type 2 Diabetes, waist circumference

\section{INTRODUCTION}

It is well known that obesity or excess adiposity and more specifically abdominal adiposity is positively associated with Type 2 Diabetes risk. ${ }^{1}$ However, there are different ways of measuring abdominal adiposity. Anthropometrically derived measurements like waist circumference (WC), waist hip ratio (WHR), waist height ratio (WHtR) are widely used in epidemiological studies, because of their strong positive association with both abdominal adipose tissue and disease risk. ${ }^{2-5}$ Moreover, these measurements are simple, inexpensive and could be used in a larger sample. However, to the best of our knowledge, no comparative study has been done in India considering different anthropometrically derived adiposity measures to study the association with Type 2 Diabetes. In view of the above consideration, the objectives of the present study are to examine the association of different adiposity measures with Type 2 Diabetes and to find out the best adiposity measure in assessing Type 2 Diabetes. 


\section{METHODS}

A sample of 187 adult males; aged 25-67 years old; from an urban area of West Bengal, India were examined between October 2007 and August 2008. In this crosssectional study, individuals were informed by letters and oral communication regarding the aims of the study and interested individuals were incorporated. However, individuals under medication were excluded. Informed consent was obtained from all participants before the work commenced. Anthropometric measurements viz. height (HT), weight (WT), minimum waist circumference (MWC), abdominal circumference (AC), hip circumference (HC) was taken following standard techniques. ${ }^{6}$ In brief, all measurements were taken with little clothing and barefooted. During the measurement of $\mathrm{HT}$, the subject stands on a flat surface with the head in Frankfurt Horizontal Plane. WT was measured with the subject stands still over the center of the platform of weighing machine with body weight evenly distributed between both feet. However, we have measured WC at two anatomical sites, one at the level of the greatest anterior extension of the abdomen in horizontal plane and termed as $\mathrm{AC}$ and the other one at the level of the natural waist, which was the narrowest part of the torso and termed as MWC. HC was measured at the level of maximum extension of the hip. WHtR, WHR, body mass index (BMI), and conicity index (Cl) were calculated subsequently. HT was measured to the nearest $0.1 \mathrm{~cm}$ using moveable anthropometer. Circumference measurements were made to the nearest $0.1 \mathrm{~cm}$ using inelastic steel tape. WT was measured to the nearest $0.5 \mathrm{~kg}$ using weighing machine. Intra-observer error was calculated. Technical error of measurements (TEM) values was found to be between 0.000 and 0.077 considering all the anthropometric variables. ${ }^{7}$ Fasting glucose (FPG) concentration and postload glucose concentration 2-hours after a 75-g OGTT (2hPG) were measured by Glucometer (Advance Micro-draw, Hypoguard, Minneapolis, MN 55439, USA). Reliability of measurement was checked on a regular basis. Subjects were defined as having diabetes if they met the American Diabetes Association criteria. ${ }^{8}$ Descriptive statistics were performed by mean and standard deviation (SD). To compare the independent association of different adiposity measures with Type 2 Diabetes, we calculated odd ratios (ORs) for each measurement using tertile in simple logistic regression analysis. Areas under the receiver operating characteristic (ROC) curves were calculated to understand the ability of each adiposity measure to assess Type 2 Diabetes. Statistical analysis was performed using the Statistical Package for Social Sciences version 9.0.0 (SPSS Inc., Chicago, IL, USA). A p-value of $<0.05$ was considered as significant.

\section{RESULTS}

The study population included 187 adult males aged 25-67y and the mean age was 44.66y (SD $\pm 9.35 y)$. The mean and standard deviation of anthropometric and blood glucose variables are presented in table 1 . With 23 participants identified as having Type 2 Diabetes, the prevalence of Type 2 Diabetes in the study population was $12.3 \%$. Comparison of the prevalence of Type 2 Diabetes in lowest vs. highest tertile are presented in table 2 . The odd ratios

Table 1. Characteristics of the study population.

\begin{tabular}{lll}
\hline Variables & Mean & SD \\
\hline Height $(\mathrm{cm})$ & 164.66 & 6.44 \\
\hline Weight $(\mathrm{kg})$ & 65.09 & 10.88 \\
\hline $\begin{array}{l}\text { Minimum waist circumfer- } \\
\text { ence (cm) }\end{array}$ & 84.30 & 8.15 \\
\hline $\begin{array}{l}\text { Abdominal circumference } \\
\text { (cm) }\end{array}$ & 89.80 & 9.19 \\
\hline $\begin{array}{l}\text { Maximum hip circumference } \\
\text { (cm) }\end{array}$ & 91.32 & \\
\hline Waist hip ratio & 0.92 & 6.44 \\
\hline Waist height ratio & 0.51 & 0.05 \\
\hline Body mass index (kg/m2) & 23.94 & 0.05 \\
\hline Abdominal hip ratio & 0.98 & 3.27 \\
\hline Conicity index & 1.23 & 0.06 \\
\hline Fasting glucose (mg/dl) & 105.69 & 0.06 \\
\hline Postload glucose (mg/dl) & 131.29 & 25.59 \\
\hline
\end{tabular}

Table 2. Comparison of the prevalence of Type 2 Diabetes in lowest vs. highest tertile.

\begin{tabular}{|c|c|c|c|c|}
\hline \multirow{3}{*}{ Variables } & \multicolumn{4}{|c|}{ Tertile } \\
\hline & \multicolumn{2}{|c|}{ Lowest } & \multicolumn{2}{|c|}{ Highest } \\
\hline & $\mathrm{n}$ & $\%$ & $\mathbf{N}$ & $\%$ \\
\hline $\begin{array}{l}\text { Minimum waist circum- } \\
\text { ference }(\mathrm{cm})\end{array}$ & 6 & 26.07 & 14 & 60.87 \\
\hline $\begin{array}{l}\text { Abdominal circumfer- } \\
\text { ence }(\mathrm{cm})\end{array}$ & 2 & 8.70 & 14 & 60.87 \\
\hline Waist hip ratio & 5 & 21.74 & 11 & 47.83 \\
\hline Waist height ratio & 5 & 21.74 & 13 & 56.52 \\
\hline $\begin{array}{l}\text { Body mass index (kg/ } \\
\mathrm{m} 2)\end{array}$ & 5 & 21.74 & 11 & 47.83 \\
\hline Conicity index & 3 & 13.04 & 10 & 43.48 \\
\hline
\end{tabular}

along with $95 \%$ confidence intervals $(95 \% \mathrm{Cl})$ of $\mathrm{MWC}, \mathrm{AC}$, $\mathrm{BMI}, \mathrm{WHR}, \mathrm{WHtR}$ and $\mathrm{Cl}$ for Type 2 Diabetes are shown in table 3. Compared to the lowest tertile, odd ratios for Type 2 Diabetes was 2.75 (95\% Cl: 1.45 to 5.23) with $\mathrm{AC}$ in the highest tertile, $1.86(95 \% \mathrm{Cl} 1.05-3.32)$ with WHtR and 1.83 (95\% Cl: 1.03 to 3.26 ) with MWC in the highest tertile. Thus, the higher risk of Type 2 Diabetes was associated with increasing AC. However, the odd ratios of WHR, BMI and $\mathrm{Cl}$ for diabetes were not statistically significant $(p>0.05)$. The area under the ROC curves in assessing Type 2 Diabetes for adiposity measures are shown in table 4 . Apart from the $\mathrm{BMI}$ and $\mathrm{Cl}$, areas under the ROC curves of all adiposity measures were significantly higher than the non-effect value 0.5. However, the area under the ROC curve for AC (AUC $0.68,95 \% \mathrm{Cl} 0.57$ to 0.79 ) was larger than those of other measures in assessing Type 2 Diabetes. 
Table 3. Odd ratios of different adiposity measures for Type 2 Diabetes.

\begin{tabular}{|lllll|}
\multicolumn{1}{|c}{ Variables } & OR & \multicolumn{2}{c}{$95 \% \mathrm{Cl}$} & p \\
& & $\begin{array}{l}\text { Lower } \\
\text { Bound }\end{array}$ & $\begin{array}{l}\text { Upper } \\
\text { Bound }\end{array}$ & \\
\hline $\begin{array}{l}\text { Minimum waist circum- } \\
\text { ference (cm) }\end{array}$ & 1.83 & 1.03 & 3.26 & 0.03 \\
\hline $\begin{array}{l}\text { Abdominal circumfer- } \\
\text { ence (cm) }\end{array}$ & 2.75 & 1.45 & 5.23 & 0.01 \\
\hline $\begin{array}{l}\text { Waist hip ratio } \\
\text { Waist height ratio }\end{array}$ & 1.58 & 0.91 & 2.76 & 0.11 \\
\hline $\begin{array}{l}\text { Body mass index (kg/ } \\
\left.\text { m }^{2}\right)\end{array}$ & 1.59 & 1.05 & 3.32 & 0.03 \\
\hline Conicity index & 1.58 & 0.91 & 2.77 & 0.11 \\
\hline
\end{tabular}

Table 4. Area under the ROC curves of different adiposity measures in assessing Type 2 Diabetes.

\begin{tabular}{|c|c|c|c|c|}
\hline \multirow[t]{2}{*}{ Variables } & \multirow[t]{2}{*}{ AUC } & \multicolumn{2}{|c|}{$95 \% \mathrm{Cl}$} & \multirow[t]{2}{*}{$p$} \\
\hline & & Lower Bound & Upper Bound & \\
\hline $\begin{array}{l}\text { Minimum waist } \\
\text { circumference }(\mathrm{cm})\end{array}$ & 0.63 & 0.51 & 0.76 & 0.03 \\
\hline $\begin{array}{l}\text { Abdominal circum- } \\
\text { ference }(\mathrm{cm})\end{array}$ & 0.68 & 0.57 & 0.79 & 0.01 \\
\hline Waist hip ratio & 0.64 & 0.53 & 0.75 & 0.02 \\
\hline Waist height ratio & 0.63 & 0.51 & 0.75 & 0.02 \\
\hline $\begin{array}{l}\text { Body mass index } \\
\left(\mathrm{kg} / \mathrm{m}^{2}\right)\end{array}$ & 0.61 & 0.48 & 0.74 & 0.09 \\
\hline Conicity index & 0.62 & 0.50 & 0.73 & 0.06 \\
\hline
\end{tabular}

\section{DISCUSSION}

This is the first study comparing the association of six adiposity measures i.e. BMI, MWC, AC, WHR, WHtR and $\mathrm{Cl}$ with Type 2 Diabetes in Asian Indian males. The logistic regression and receiver operating characteristic curve analysis revealed that AC was the best adiposity measure for predicting Type 2 Diabetes. Although, most studies demonstrated that WC may be a better indicator of Type 2 Diabetes risk than other central adiposity measures, it should be noted that there was no universal landmark to measure WC. ${ }^{9,10}$ Thus, the anatomical landmark used to measure WC varied from one study to another and they used the term WC generally, irrespective of the anatomical site used to measure the WC. ${ }^{11,12}$ Moreover, studies also revealed that the differences in anatomical sites for the measurement of WC have different magnitude in the relationship with adipose tissue distribution and metabolic risk factors. ${ }^{13,14}$ However, no previous attempt has been made among Asian Indians to investigate the association of Type 2 Diabetes risk with the difference in WC measured at different sites. The results of the present study showed that compared to other central adiposity measures, AC was better with highest odd ratio for Type 2 Diabetes, followed by WHtR and MWC. Due to the lack of studies on $A C$, comparison with the present study remains unsolved. Some studies revealed that WC was better predictor of
Type 2 Diabetes compared to WHtR. ${ }^{11,15,16}$ Contrary to that, some other studies revealed WHtR was better predictor of Type 2 Diabetes compared to WC. ${ }^{17,18}$ Conversely, in the present study we have found that both MWC and WHtR have almost similar association with Type 2 Diabetes (MWC, OR 1.83; 95\% Cl $1.03-3.26$ Vs WHtR, 1.86; 95\% Cl 1.05 - 3.32).Though, it was difficult to compare the findings of our study with all these studies because of the difference in WC measurements site. However, when we compared our findings with the studies, that have considered WC and measured at the narrowest part of the torso (i.e. MWC in the present study), and WHtR, similar result has been observe. ${ }^{12,14}$ Moreover, corroborating with the previous study, present study also revealed that BMI was not a useful measure in Asian Indians. ${ }^{19}$ The lack of association between BMI and Type 2 Diabetes in others ethnic group has been observed in some recent studies also. ${ }^{15,20}$ Like $\mathrm{BMI}, \mathrm{WHR}$ and $\mathrm{Cl}$ were also demonstrated lack of significant associations with Type 2 Diabetes. Study revealed that WHR was strongly associated with muscle mass and pelvic structure. ${ }^{21}$ The lack of association between $\mathrm{Cl}$ and Type 2 Diabetes in the present study might be due to the fact that, $\mathrm{Cl}$ takes into account the overall adiposity and Asian Indians have a tendency towards more abdominal adipose tissue deposition. ${ }^{22}$ Furthermore, the ROC curve analysis revealed that the $A C$ as a surrogate measure of central adiposity not only revealed the highest odd ratio for Type 2 Diabetes, but also have higher assessment ability of Type 2 Diabetes, compared to other central adiposity measures. Thus, the cardinal feature of the present study was that the WC, measured at the level of greatest anterior extension of the abdomen was more strongly associated with Type 2 Diabetes risk compared the narrowest part of the torso. Moreover, AC as a simple proxy measure of visceral adipose tissue differs from the MWC in being the maximum circumference of the abdomen and, therefore, could be a better indicator of abdominal adipose tissue. ${ }^{2}$

\section{CONCLUSION}

Comparison of different adiposity measures revealed that AC had the highest odd ratio for Type 2 Diabetes, and was also the best central adiposity measure in assessing Type 2 Diabetes. Since, the present study was cross-sectional and restricted to males, further studies on the females as well as in other ethnic groups is necessary to find out the best adiposity measure of Type 2 Diabetes. Because, results from such studies could be used to develop Type 2 Diabetes prevention strategies.

\section{ACKNOWLEDGEMENT}

The authors are grateful to the all participants. The authors are also grateful to the UGC, Govt. of India, for providing financial support. 


\section{REFERENCES}

1. Mannan MA, Rahman MS, Siddiqui NI. Obesity management in patients with Type 2 Diabetes mellitus. Mymensingh Med J 2004;13:95-9.

2. Ribeiro-Filho FF, Faria AN, Azjen S, Zanella MT, Ferreira SRG. Methods of estimation of visceral fat: advantages of ultrasonography. Obes Res 2003;11:1488-94.

3. Lee CM, Huxley RR, Wildman RP, Woodward M. Indices of abdominal obesity are better discriminators of cardiovascular risk factors than BMI: a meta-analysis. J ClinEpidemiol 2008;61:646-53.

4. Ghosh JR,Basak S, Bandyopadhyay AR. A study on nutritional status among young adult Bengalee females of Kolkata: effect of menarcheal age and per capita income. Anthrop Anz 2009;67:13-20.

5. Moni MA, Rahman MA, Haque MA, Islam MS, Ahmed K. Blood pressure in relation to selected anthropometric measurements in senior citizens. Mymensingh Med J 2010;19:254-8.

6. Lohman TG, Roche AF, Martorell R, editors. Anthropometric Standardization Reference Manual. Abridged ed. Champaign, IL: Human Kinetics Books; 1988.

7. Ulijaszek SJ,Lourie JA. Intra and inter observer error in anthropometric measurement. In: Ulijaszek SJ,Mascie-Taylor CGN, editors. Anthropometry: the individual and the population. Cambridge: Cambridge University Press; 1994.

8. American Diabetes Association. Diagnosis and classification of diabetes mellitus. Diabetes Care 2006;29:43S-8S.

9. Lopatynski J, Mardarowicz G, Szczesniak G. A comparative evaluation of waist circumference, waist-to-hip ratio, waist-to-height ratio and body mass index as indicators of impaired glucose tolerance and as risk factors for type-2 diabetes mellitus. Ann Univ Mariae Curie Sklodowska 2003;58:413-9.

10. Wang Y, Rimm EB, Stampfer MJ, Willett WC, Hu FB. Comparison of abdominal adiposity and overall obesity in predicting risk of Type 2 Diabetes among men. Am J ClinNutr 2005;81:555-63.

11. Stevens J, Couper D, Pankow J, Folsom AR, Duncan BB, Nieto FJ, et al. Sensitivity and specificity of anthropometrics for the prediction of diabetes in a biracial cohort. Obes Res 2001;9:696-705.

12. Sargeant LA, Bennett FI, Forrester TE, Cooper RS, Wilks RJ. Predicting incident diabetes in Jamaica: the role of anthropometry. Obes Res 2002;10:792-8
13. Wang J, Thornton JC, Bari S, Williamson B, Gallagher D, Heymsfield SB, et al. Comparisons of waist circumferences measured at 4 sites. Am J ClinNutr 2003;77:379-84.

14. Esmaillzadeh A, Mirmiran P, Azizi F. Waist-to-hip ratio is a better screening measure for cardiovascular risk factors than other anthropometric indicators in Tehranian adult men. Int J Obes Relat Metab Disord 2004;28:1325-32.

15. Deloumeaux J, Ninin E, Foucan L. Anthropometric parameters and Type 2 Diabetes: a case-control study in a Guadeloupean population. Diabetes Metab 2004;30:75-80.

16. Wang Z, Hoy WE. Body size measurements as predictors of Type 2 Diabetes in Aboriginal people. Int J ObesRelatMetabDisord 2004;28:1580-4.

17. Sayeed MA, Mahtab H, Latif ZA, Khanam PA, Ahsan KA, Banu A, et al. Waist-to-height ratio is a better obesity index than body mass index and waist-to-hip ratio for predicting diabetes, hypertension and lipidemia. Bangladesh Med Res Counc Bull 2003:29:1-10.

18. Hadaegh F, Zabetian A, Harati H, Azizi F. Waist/height ratio as a better predictor of Type 2 Diabetes compared to body mass index in Tehranian adult men-a 3.6 year prospective study. Exp ClinEndocrinol Diabetes 2006;114:310-5.

19. Snehalatha C, Viswanathan V, Ramachandran A. Cutoff values for normal anthropometric variables in Asian Indian adults. Diabetes Care 2003;26:1380-4.

20. Mansour AA, Al-Jazairi MI. Cut-off values for anthropometric variables that confer increased risk of Type 2 Diabetes mellitus and hypertension in Iraq. Arch Med Res 2007;38: 253-8.

21. Taylor RW, Keil D, Gold EJ, Williams SM, Goulding A. Body mass index, waist girth, and waist-to-hip ratio as indexes of total and regional adiposity in women: evaluation using receiver operating characteristic curves. Am J ClinNutr 1998;67:44-9.

22. Yasmin, Mascie-Taylor CG. Adiposity indices and their relationship with some risk factors of coronary heart disease in middle-aged Cambridge men and women. Ann Hum Biol 2000;27:239-48.

23. Callaway CW, Chumlea WC, Bouchard C, Himes JH, Lohman TG, Martin AD, et al. Circumferences. In: Lohman TG, Roche AF,Martorell $\mathrm{R}$, editors. Anthropometric standardization reference manual. USA: Human Kinetics Books; 1988. 